\section{THE WABASH CENTER}

JOURNAL on TEACHING

\title{
None of the Above: Nonreligious Identity in the US and Canada
}

\author{
Joel Thiessen and Sarah Wilkins-Laflamme \\ New York, NY: New York University Press, 2020 (259 pages, ISBN 978-1-4798-6080-7, \\ \$30.00)
}

\author{
Reviewed By \\ Nathan E. Fleeson \\ University of Georgia
}

None of the Above: Nonreligious Identity in the US and Canada provides a fresh look at the growing place of religious nones in society, raising questions that have yet to be answered about what has been an underrepresented group of people in religious studies. This includes asking about how we understand nonreligious identity in Canada which, despite having developed a significant non religious population earlier than the US, has largely been ignored.

Thiessen and Wilkins-Laflamme use statistical data and interviews to outline a sociological picture of nonreligious identity. Their outline includes what causes people to choose a nonreligious identity, the diverse ways one can be nonreligious, how a nonreligious identity affects sociopolitical beliefs and activity, and how those with a nonreligious identity relate to those of religious identity, and vice versa.

Thiessen and Wilkins-Laflamme also do an excellent job asking about how regional differences affect the makeup of nonreligious identity for various regions. This is one of the many reasons for incorporating a survey of both Canada and the US, but also of regional differences within the countries. The authors draw important connections between how the (non) religious identity of a region plays a role in how easy it is to be nonreligious and how it can play a role in the population's political activity.

While none of the chapters are specifically oriented towards teaching about nonreligious identity, they contain important information to better understand the nuances of this group that will benefit students. While connected together, each chapter makes an important contribution and has a strong enough framework that it could be assigned to students on its own. This book would fit well in an upper-level sociology of religion course, but it may be a bit data heavy for more introductory or humanities-oriented courses. The authors do a great job explaining their data and its impact for understanding religious nones, but one works through a lot of graphs, predicted probabilities, and lists of data along the way.

Especially valuable to teachers of religion will be the second chapter which explores the many ways one can identify as nonreligious. For this, the authors draw on definitions of religion, looking at the categories of belonging, belief, and behavior, to argue that while religious nones may belong to the same category of "nonreligion," they can have widespread religious and spiritual beliefs and behaviors. This distinction will be important for better teaching students about religious nones. We already see the value of these distinctions at work in the chapters on sociopolitical beliefs, where Thiessen and Wilkins-Laflamme point out that belief and behavior can have a greater impact than belonging. As such, one might see how our field's struggle with defining "religion” shows up in our definitions of "nonreligion."

None of the Above: Nonreligious Identity in the US and Canada makes an important step to better understanding the diversity of nonreligious identities, how that varies between the different regions of the US and Canada, and the impacts a subtype or region can have on sociopolitical beliefs or interactions with other (non)religious identities. As such, it would make a valuable addition to any course exploring the rising group of religious nones. 